\title{
XFEM based fracture analysis of single notch reactive powder concrete specimen subjected to three point bending test
}

\author{
Patria Kusumaningrum ${ }^{*}$, Bambang Budiono ${ }^{1^{*}}$, Muhammad Fajar $^{2}$, Elitha $^{2}$ \\ ${ }^{1}$ Structural Engineering Research Group, Faculty of Civil and Environmental Engineering, Institut Teknologi Bandung, Indonesia \\ ${ }^{2}$ Civil Engineering Master Program, Faculty of Civil and Environmental Engineering, Institut Teknologi Bandung, Indonesia
}

\begin{abstract}
An extended finite element method (XFEM) for fracture problem within the finite element software ABAQUS is adopted in order to investigate the mechanical properties and fracture behaviour of RPC material. The RPC materials observed are plain RPC of $0 \%$ and steel fiber RPC (SFRPC) of $2 \%$ volume fraction. Single edge notch three-point bending (TPB) tests of RPC materials are performed. The mechanical properties of RPC with respect to single edge notch TPB test, i.e. tensile stress, CMOD, and fracture energy obtained from experiment are then compared to those obtained from numerical analysis. A good agreement is observed between the experimental and numerical results.
\end{abstract}

\section{Introduction}

Reactive powder concrete is considered as one of highperformance engineering concrete materials as it possesses excellent material properties (i.e. very high compressive strength, high modulus of elasticity, etc) due to its granular compactness and denser microstructures [1]. The composite action of RPC constituent ingredients, including quarts sand and powder, silica fume and cement paste, has complicated its fracture characteristics due to the natures of the concrete composite material. Plain RPC, like other concrete materials, possesses brittle behavior with low tensile strength, fracture energy and fracture toughness. Fracture characteristics of plain RPC is similar to that of plain concrete. To improve the fracture behavior of RPC, fibers are added into the RPC mixture. In the previous RPC researches conducted by Structural Engineering Research Group of ITB, in the framework of implementing the roadmap of research group in developing High Performance Concrete, polypropylene fibers were added into the RPC blends [2-4]. This research is a continuation of the aforementioned RPC researches. In this paper, the focus of the study is on fracture characteristics of plain RPC and steel fiber RPC (SFRPC). The presence of steel fiber in SFRPC mixture is expected to increase the ductility of SFRPC by achieving tensile strain hardening conditions due to the multiple crack-bridging process of steel fiber.

\section{Extended Finite Element Method}

Finite element method (FEM) is based on continuum approach. In FEM, discontinuities due to crack are often carried out by mesh refinement of the element (smeared crack method) or are introduced at the element edges (conventional discrete crack method). Such approaches, however, are very tedious, yet do not represent the real crack pattern as the distortion location and the discontinuity of the displacement are not correctly mapped.

In 1999, Belytschko and Black [5] and Moes et al. [6] proposed the extended finite element method (XFEM). This method is found to be more efficient in terms of calculation time, yet it simplifies the application. By considering additional degrees of freedom, discontinuities are herein described meshindependently. XFEM has been adopted within ABAQUS finite element software [7-8] and is herein applied for crack analysis of RPC materials. By definition, in XFEM the displacement field of point $x$ is approximated by [7-8]:

$$
u(x)=\sum_{i=1}^{n} N_{i}(x) u_{i}+\sum_{j=1}^{m} N_{j}(x) \psi_{j}(x) a_{j}
$$

where $\mathrm{u}$ is the nodal displacement, $\mathrm{N}$ is the shape function, $\psi$ is the enrichment function and $\mathrm{a}$ is the enriched degrees of freedom.

As fracture damage analysis is performed, only the discontinuity of the crack shall be considered. Therefore, the enrichment function is defined in terms of the discontinuity enrichment using the Heaviside step function $H(x)$. Heaviside step function $H(x)$ is a jump function along the crack geometry in which for a location above the crack, it has a value of 1 and below it the value is -1 .

$\psi_{j}(x)=H(x)\left\{\begin{array}{cc}+1 & \text { if }\left(x-x^{\prime}\right) . n \geq 0 \\ -1 & \text { otherwise }\end{array}\right\}$

where point $x$ represents an integration point in the finite element method, $x$ ' is the point on the crack the nearest to point $\mathrm{x}$ on $\Gamma$,and $\mathrm{n}$ is the normal vector to $\Gamma$ at the point $\mathrm{x}$ '. If we assume $\xi$ is the distance between $\mathrm{x}$ and

\footnotetext{
*Corresponding author: patria@si.itb.ac.id
} 
$\mathrm{x}^{\prime}$ in such a way that $\xi=\left(x-x^{\prime}\right) . n$, the displacement field of point $x$ can therefore be written as:

$$
\begin{aligned}
u(x)=\sum_{i=1}^{n} N_{i}(x) & u_{i} \\
& +\sum_{j=1}^{m} N_{j}(x)\left(H(\xi)-H\left(\xi_{j}\right)\right) a_{j}
\end{aligned}
$$

The discontinuous elements, instead of having additional nodal degrees of freedom such like in the conventional discrete crack method, now have a new set of nodes over their initial set of nodes. When an element is separated by a crack, two separate elements are then created. Each of the separate elements now has independent displacement field of $x$, describing the presence of discontinuity as result of crack formation.

Adopted within ABAQUS, XFEM offers two approaches to model fracture propagation, i.e. virtual crack closing technique (VCCT) which based on Linear elastic fracture mechanics (LEFM) approach and cohesive zone model (CZM). In this study, the latter approach, CZM, is incorporated. The CZM uses traction-separation criterion based on damage mechanics where damage properties are specified as part of the bulk material definition. This approach is applicable for both brittle and ductile failures. Maximum principal stress (MAXPS) is the damage initiation criteria used in this study, with the damage criterion follows that of tensile damage criterion of the Concrete Damage Plasticity (CDP) material derived for RPC materials [9-10]. The damage model is herein defined as,

$$
\begin{aligned}
\sigma=(1-d) \bar{\sigma}= & (1 \\
& -d) C \varepsilon
\end{aligned}
$$

where $\sigma$ is the stress tensor, $\bar{\sigma}$ is the effective stress tensor, $\varepsilon$ is the strain tensor, $C$ is the stiffness tensor of material properties or elastic moduli, and $d$ is the damage parameter which ranged between 0 (no damage) and 1 (fully damaged). Crack will propagate when the critical value of maximum principal stress is reached. The formation of the crack is perpendicular to the direction of the maximum principal stress and may change its direction as it propagates.

XFEM is applicable to be used in static analysis, dynamic analysis, and low cycle fatigue analysis. It has some limitations on its application, i.e. only one crack in an element, no intersection of cracks, slope of crack propagation is limited to $90^{\circ}$, and it cannot be combined with composite solid elements or adaptive remeshing.

\section{Material and Specimens Preparations}

\subsection{RPC Matrix}

The RPC matrix is adopted from a mix proposed by Naibaho et al. [2] with the modification on lower water content and $\mathrm{w} / \mathrm{c}$ ratio. The cementitious materials used in this RPC mixture are Portland cement type I and silica fume (SF). The SF incorporated into the mixture is Sika Fume from PT SIKA Indonesia. Lampung quartz sand with the largest diameter of $600 \mu \mathrm{m}$ (pass through no.30 filter) and quartz powder of 5-10 $\mu \mathrm{m}$ diameter (pass through no. 200 filter) are used as fine and finer aggregates, respectively. There is no coarse aggregate in the mixture. The superplasticizer (SP) used is Viscocrete 7097 from PT SIKA Indonesia. The resulting water/cementitious ratio is 0.17 , with 0.19 water content. The RPC composition made from locally available raw materials is given in Table 1 .

Table 1. RPC Mixture Composition

\begin{tabular}{|c|c|c|c|c|c|c|}
\hline \multirow{2}{*}{ Cement } & \multirow{2}{*}{ Silica } & \multicolumn{2}{|c|}{ Quartz } & \multirow{2}{*}{ Superplasticizer } & \multirow{2}{*}{ Water } & \multirow{2}{*}{ w/c } \\
\cline { 3 - 4 } & Fume & Sand & Powder & & & \\
\hline 1.00 & 0.12 & 1.12 & 0.07 & 0.029 & 0.19 & 0.17 \\
\hline
\end{tabular}

\subsection{Steel Fibers}

The steel fiber used in this study is Dramix 3D 65/35. Dramix 3D $65 / 35$ is a hooked end type of fiber with properties given in Table 2. In this paper, the fiber volume fraction used in the SFRPC mixture is $2 \%$.

Table 2. Steel Fiber Properties

\begin{tabular}{|c|c|c|}
\hline Material Properties & Size & Unit \\
\hline Type & Dramix 3D 65/35 BG \\
\hline Length, $l$ & 35 & $\mathrm{~mm}$ \\
\hline Diameter, $d$ & 0.55 & $\mathrm{~mm}$ \\
\hline Aspect ratio, $l / d$ & 65 & \\
\hline Tensile Strength, $f t$ & $1345 \pm 7.5 \%$ & $\mathrm{MPa}$ \\
\hline Young's Modulus, $E$ & 210000 & $\mathrm{MPa}$ \\
\hline Density, $\rho$ & 7800 & $\mathrm{~kg} / \mathrm{m} 3$ \\
\hline
\end{tabular}

\subsection{Specimen Preparations}

Two mixtures are prepared in this study, i.e. plain RPC with $0 \%$ fiber and SFRPC with $2 \%$ steel fiber volume fraction. For each mixture, three specimens of flexural CMOD tests are prepared. The specimen is prismatic of $700 \times 150 \times 80 \mathrm{~mm}$ dimension with a notch of $40 \mathrm{~mm}$ long centered on the bottom side made using $4 \mathrm{~mm}$ thick metal blade electric saw.

Before hardened, plastic sheets are applied on top of the specimens to prevent the moisture lost. After the cast is taken out, each of the specimens are cured for 48 hours inside $90^{\circ} \mathrm{C}$ of hot water, then cured inside normal temperature water $\left(\sim 20^{\circ} \mathrm{C}\right)$ for the rest of it until it reaches 28 days.

\section{Single Edge Notch Three-Point Bending Test Set Up}

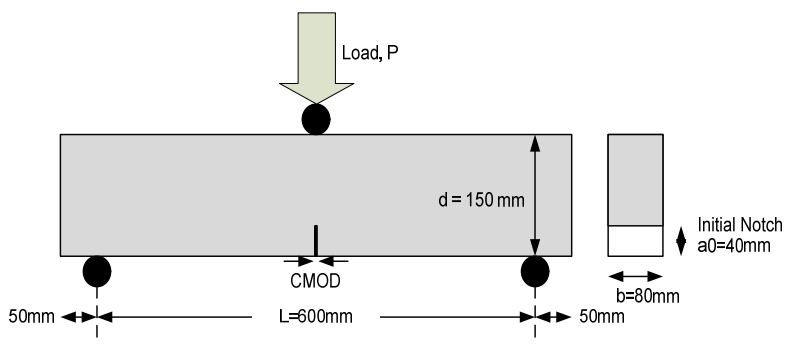

Fig 1. Single Edge Notch TPB Test Set Up 
Single edge notch three-point bending (TPB) flexural tests on RPC materials are carried out based on RILEM TC89-FMT by using MTS hydraulic universal testing machine (UTM) with a capacity of 200 ton. Distance between rollers is $600 \mathrm{~mm}$. The details of the single edge notch TPB test setup are presented in Figure 1. As shown in Figure 2, a clip gauge extensometer is mounted on the notch to measure the crack mouth opening displacement (CMOD) of the notch.

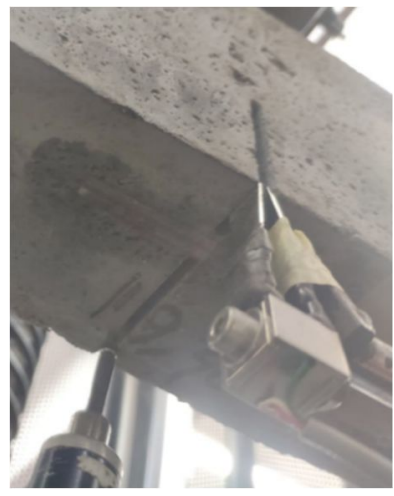

Fig 2. Clip Gauge Extensometer Mounting

\section{Numerical Model}

\subsection{Material Model}

The RPC materials, both the plain RPC and SFRPC are modeled using concrete damage plasticity (CDP) material using processed data obtained from the experimental results.

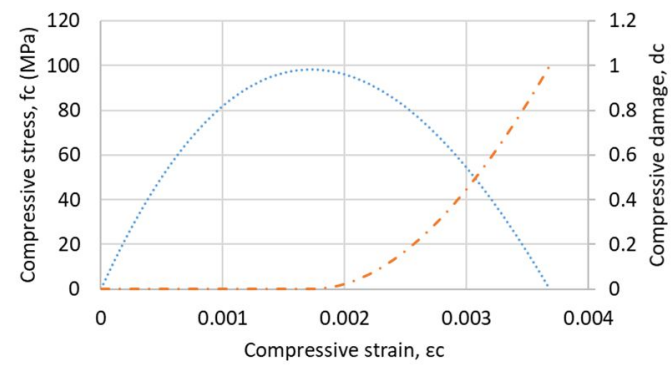

….... Compressive stress, fc _. - Compressive damage, $\mathrm{dc}$

(a)

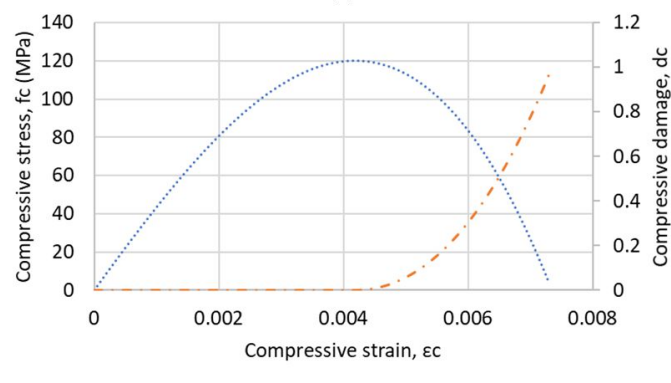

Compressive stress, fc -.- Compressive damage, dc

(b)

Fig 3. Compressive Stress Input of CDP for (a) RPC and (b) SFRPC materials

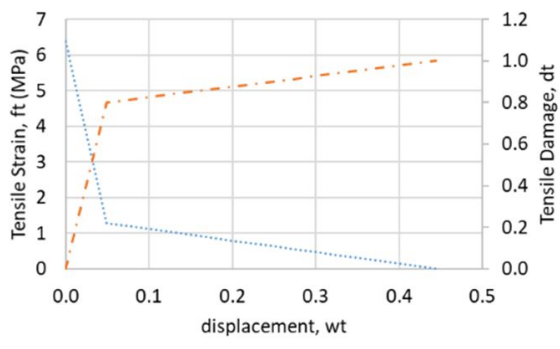

........ displacement, wt _-.- Tensile Damage, dt

(a)

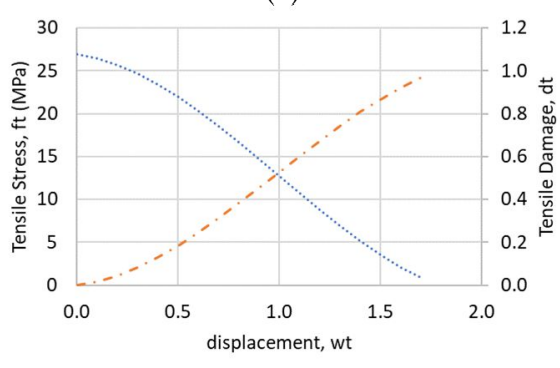

........ displacement _-.- Tensile Damage

(b)

Fig 4. Tensile Stress Input of CDP for (a) RPC and (b) SFRPC materials

Compressive behaviors of both RPC and SFRPC are modeled in a form of compressive stress-strain relation as given in Figure 3, whereas its tensile behaviors are given in Figure 4.

\subsection{Single Notch TPB Numerical Model}

Single notch TPB is modelled numerically using ABAQUS finite element software. RPC beam is modelled using C3D8R solid elements whereas the loading plate and supports are modeled using rigid elements. Non-uniform mesh sizes are incorporated into the model in such a way that the mesh size is smaller near the notch to capture better crack propagation. The numerical model of single notch TPB is shown in Figure 5. The output of this finite element model is the reaction force and crack mouth opening displacement (CMOD).

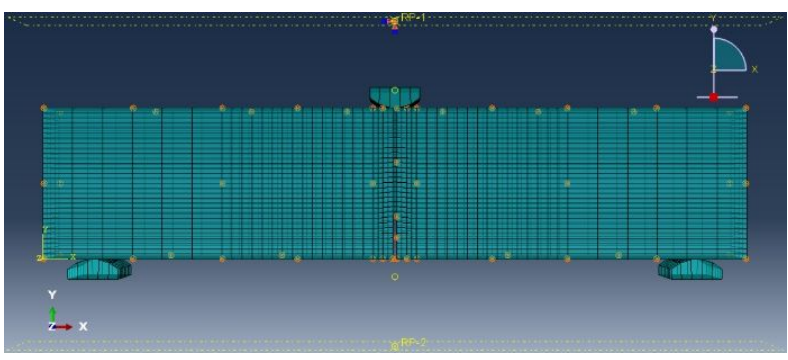

Fig 5. Numerical Model of Single Edge Notch TPB Test

\section{Results}

This section presents the numerical results obtained from FEM and XFEM modeling of single notch TPB 
test. Validation is provided by comparing numerical results obtained with the experimental data.

The FEM results of single notch RPC specimen subjected to three-point bending test are given in Figure 6 . The area under the loading point sustains compressive stress (Fig. 6b). Tensile stress concentration occurs at the notch tip (Fig. 6c) which grows as the load increases.

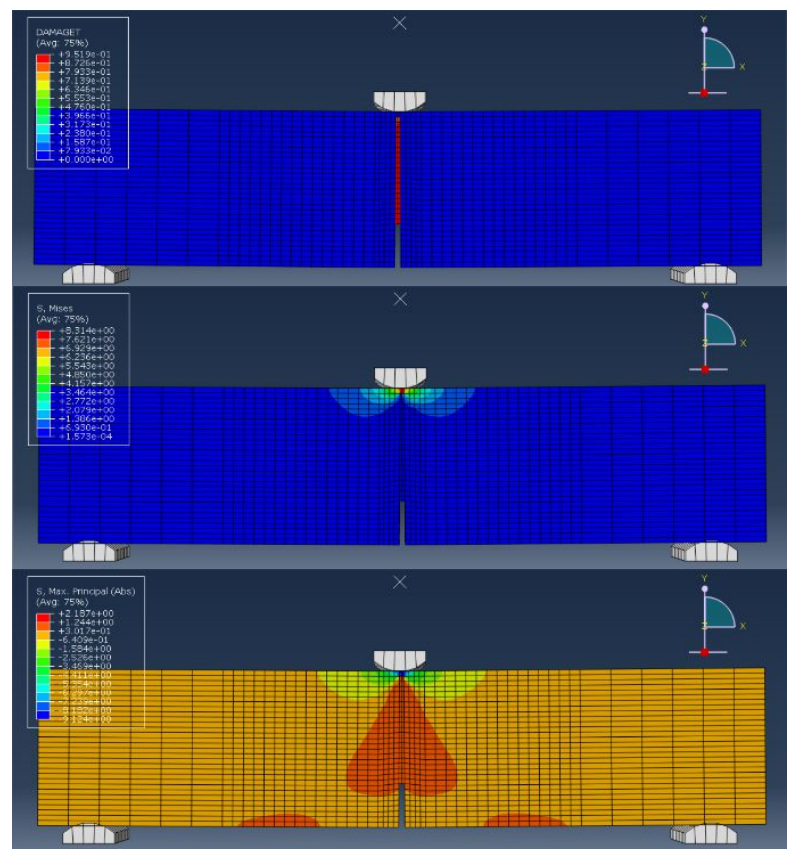

Fig. 6 FEM Results of CMOD Test of RPC Material (a) Tensile Damage (b) Von Mises Stress (c) Maximum Principal Stress

When the single notch RPC specimen is subjected to three-point bending test, numerical results of XFEM analysis are shown in Figure 7. Similar to that of FEM, the area under the loading point sustains compressive stress (Fig. 7b). However, tensile stress concentration occurs at the crack tip. It moves following the crack growth (Fig. 7c) with the intensity increases as a function of load.

XFEM predicts the crack pattern of the RPC specimen as shown in Fig. 7d. By XFEM, stress concentration is no longer at the notch tip but at the crack tip and moves as the crack grows. The crack grows from the tip of the notch to the loading point. This result agrees well with the experiment as the specimen is split right at the middle of specimen following the notch (Fig. $8)$.

The loads and tensile stresses of RPC specimen obtained from FEM and XFEM numerical analyses and single notch TPB experiment are plotted against crack mouth opening displacement (CMOD) as shown in Figure 9. The plot comprises three stages of behavior. Stage 1 is the linear stage. In stage 1 , the deflection increases linearly along with the load increment. The crack is opened but it does yet not propagate. Stage 2 is the nonlinear stage. The slope of the plot starts to reduce until it reaches its peak. In this stage, a fracture zone develops due to the presence of microcracks and crack propagation occurs in slow rate. Stage 3 is known as the strain softening zone. In this stage crack propagates rapidly due to high intensity stress concentration that occurs in a narrow zone in between notch tip and loading point. The stress concentration is higher as the load carrying capacity decreases, leading to a failure of the specimen.

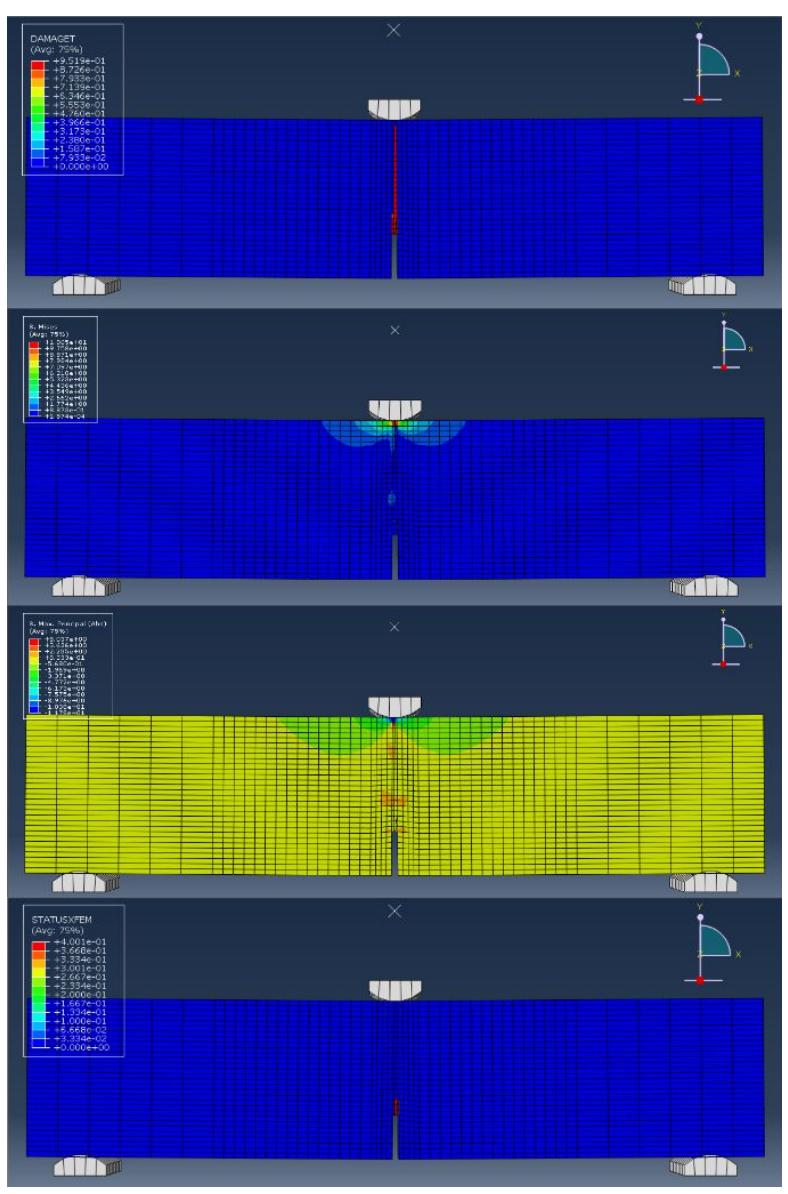

Fig. 7 XFEM Results of CMOD Test of RPC Material (a) Tensile Damage (b) Von Mises Stress (c) Maximum Principal Stress (d) Crack Pattern

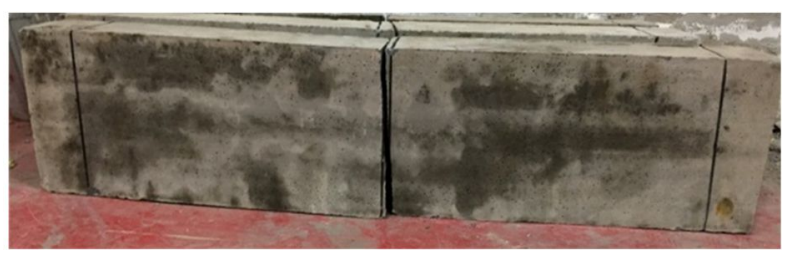

Fig. 8 RPC Specimen After Being Subjected to Single Notch TPB Test

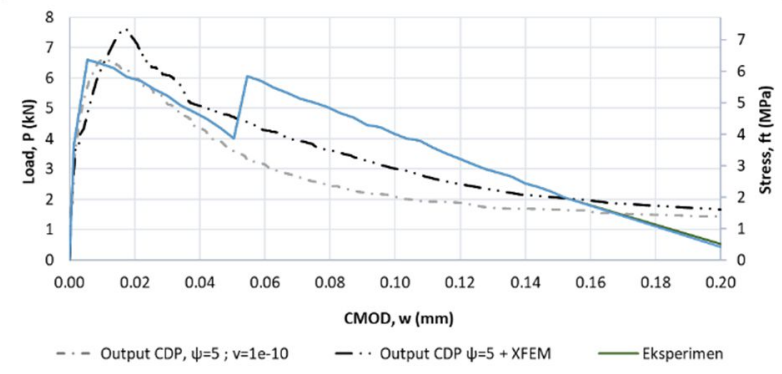

Fig. 9 Load and Stress vs CMOD of RPC Specimen 
The area under the Load-CMOD curve in Figure 9 represents energy required to break the RPC specimen. Herein, XFEM provides better approach than conventional FEM as the energy required deviates by only $1.1 \%$ less than the experimental data, while FEM deviates by $22.1 \%$ less. Fracture energy $\left(G_{f}\right)$ is defined as the area under the tensile stress-CMOD curve. Based on experiment, the $G_{f}$ of RPC material is $720 \mathrm{~N} / \mathrm{m}$. This $G_{f}$ is around 3 to 4 times of the normal strength concrete (NSC) [11].

The SFRPC single notch specimen with $2 \%$ steel fiber volume fraction is also tested under TPB. The FEM results are given in Figure 10. Similar condition to RPC specimen but of higher intensity, the area under the loading point sustains compressive stress (Fig. 10b) and the notch tip sustains tensile stress concentration (Fig. 10c) which increases with the load. XFEM analysis is carried out and it predicts the crack pattern of the SRPC specimen (Fig. 11d). By XFEM, stress concentration is no longer at the notch tip but at the crack tip. It moves as the crack propagates. The crack propagates from the notch tip to the middle height of the beam, slightly to the right side. This result agrees well with the experimental results as shown in Fig. 12.

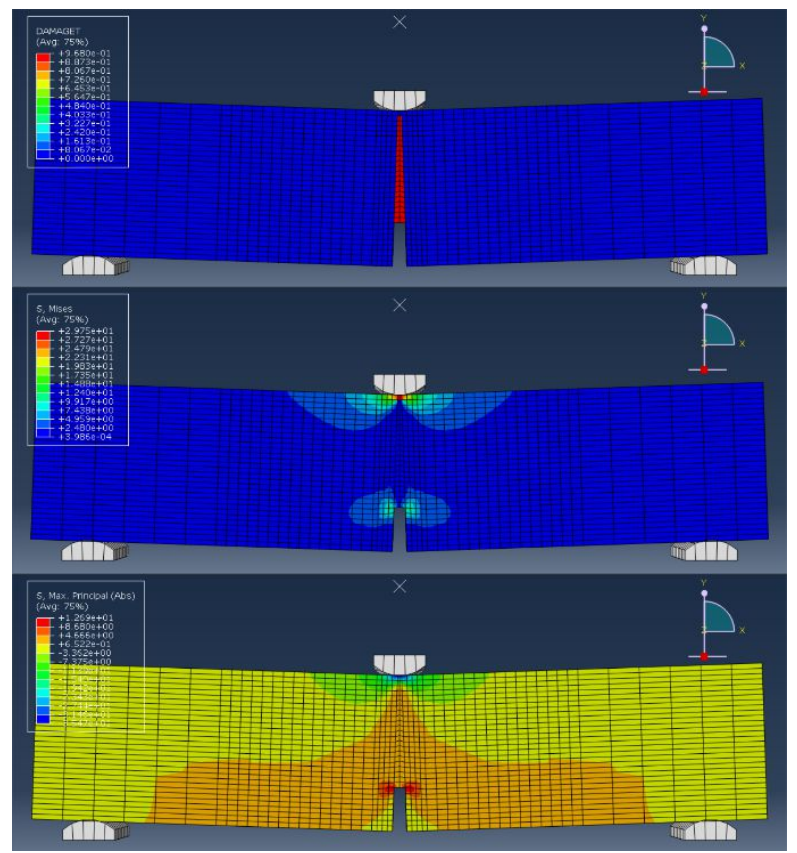

Fig. 10 FEM Results of CMOD Test of SRPC Material (a) Tensile Damage (b) Von Mises Stress (c) Maximum Principal Stress

The loads and tensile stresses of SRPC specimen obtained from FEM and XFEM numerical analyses and single notch TPB experiment are plotted against crack mouth opening displacement (CMOD) as shown in Figure 13. Similar to that of RPC specimen, the SFRPC plot comprises three stages of behavior, i.e. linear, nonlinear and strain softening stages. All the three stages of SFRPC plot are longer with higher energy dissipation than those of RPC. The presence of steel fibers in the RPC mixture increases the stiffness of the specimen (stage 1) and provides multiple crack bridging to extend the tensile strain hardening (stage 2) as well as strain softening (stage 3).

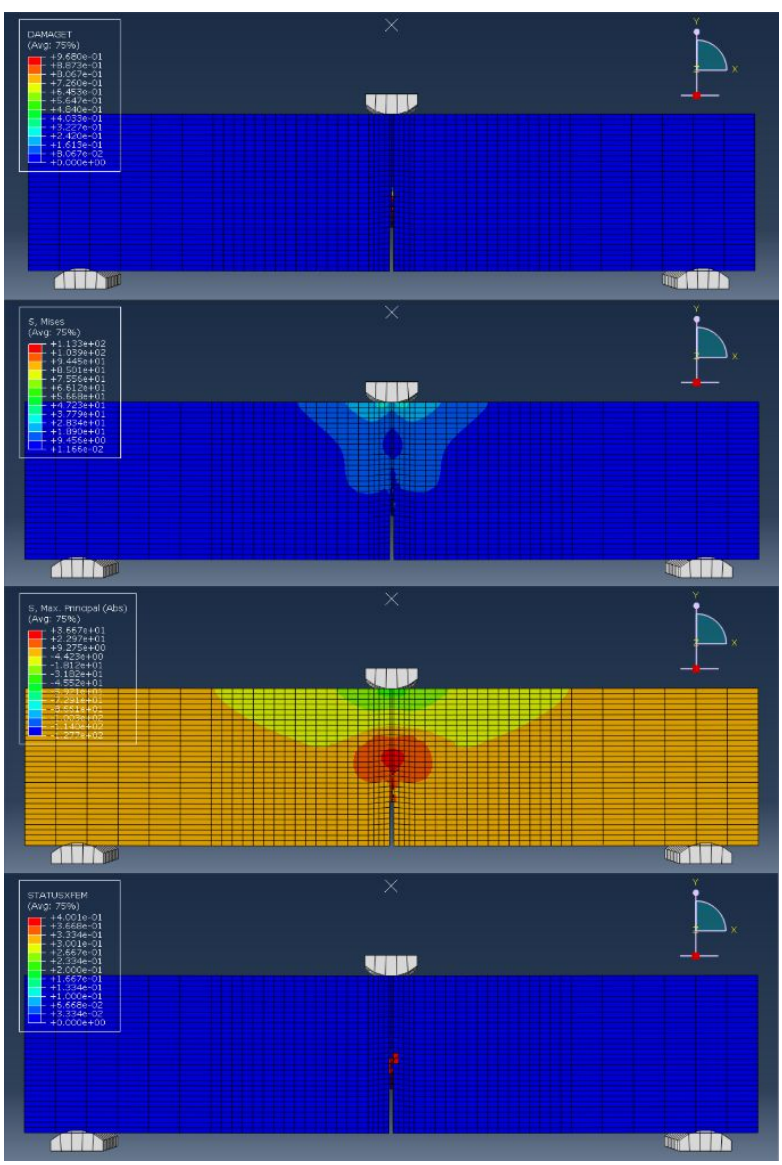

Fig. 11 XFEM Results of CMOD Test of SRPC Material (a) Tensile Damage (b) Von Mises Stress (c) Maximum Principal Stress (d) Crack Pattern

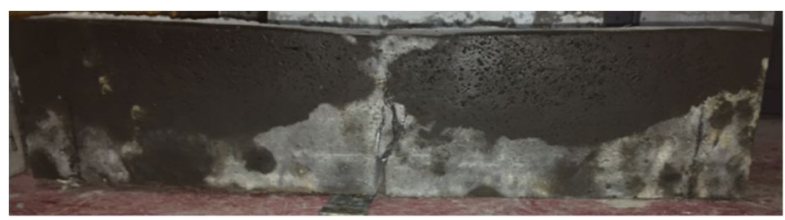

Fig. 12 SRPC Specimen After Being Subjected to Single Notch TPB Test

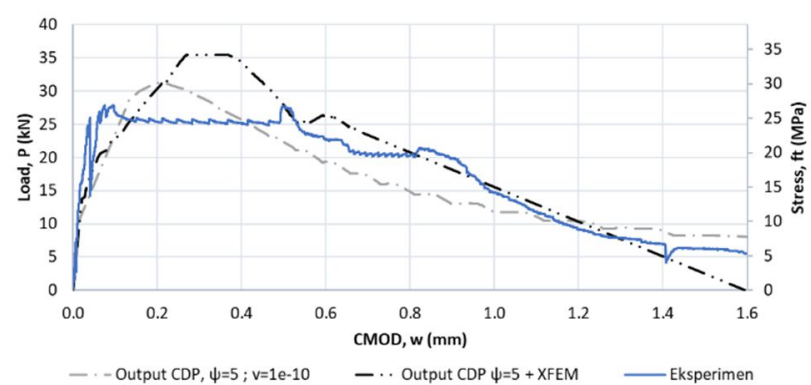

Fig. 13 Load and Stress vs CMOD of SRPC Specimen

The area under the Load-CMOD curve in Figure 13 represents energy required to break the SRPC specimen. Herein, XFEM deviates by $7.2 \%$ higher than the experimental data, while FEM deviates by $5 \%$ less. 
XFEM captures well the strain softening part as the curve coincides with the experimental result. Fracture energy $\left(G_{f}\right)$ is defined as the area under the tensile stressCMOD curve. Based on experiment, the $G_{f}$ of SRPC material is $26930 \mathrm{~N} / \mathrm{m}$, which is 37 times of the RPC.

\section{Conclusions}

This paper investigates the fracture behavior of single notch RPC and SFRPC specimens subjected to TPB. Numerical analyses are carried out using conventional FEM and XFEM. TPB experiments on single notch RPC and SFRPC specimens are also carried out to provide benchmark for the numerical analysis. It is found that XFEM provides better approach than conventional FEM in terms of stiffness prediction, energy dissipation, fracture energy and the fracture behavior of RPC and SFRPC materials.

\section{References}

1. P. Richard, and M. Cheyrezy, Cement and Concrete Research 25 (7) 1501 - 1511

2. P.R. Naibaho, B. Budiono, A. Surono, and I. Pane., Konferensi Nasional Teknik Sipil 7 Universitas Sebelas Maret, Surakarta, Indonesia, (2013).
3. M.J. Rahman, Perilaku histeretik pilar berongga persegi jembatan dengan reactive powder concrete, Dissertation, Civil Engineering ITB, Bandung, (2015).

4. S.A. Nurjannah, Perilaku histeretik sub assemblage balok-kolom reactive powder concrete prategang parsial, Dissertation, Civil Engineering, ITB, Bandung, Indonesia, (2016).

5. T. Belytschko and T. Black., Int J. N. M. E, 45, no. 5, 601-620.

6. N. Moës, J. Dolbow, and T. Belytschko, Int J. N. M. E, 46, no. 1, 131-150, (1999).

7. B.L. Karihaloo, and Q.Z. Xiao, Comp. Struc. 81 119-129, (2003).

8. E. Giner, N. Sukumar, J.E. Tarancón, and F.J. Fuenmayor, Engg. Fract. Mech. 76 347-368, (2009).

9. P. Kusumaningrum, and M. Fajar, Int. Conf. in Commemoration of $20^{\text {th }}$ Anniversary of the 1999 Chi-Chi Earthquake, Taipei, Taiwan, (2019).

10. M. Fajar, Kajian perilaku plain dan steel fiber reactive powder concrete dengan aplikasi pemodelan elemen pilar jembatan, Thesis, Civil Engineering ITB, Bandung, Indonesia, (2019).

11. J. Lee and M.M. Lopez, Int. J. C. S. M. 8 (2) 129-139, (2014) 